\title{
Epidemiology of Syncope/Collapse in Younger and Older Western Patient Populations
}

\author{
Rose Anne Kenny*, Jaspreet Bhangu, Bellinda L. King-Kallimanis \\ From School of Medicine and Institute of Neuoroscience, Trinity College, St. James's Hospital, Dublin, Ireland
}

\begin{abstract}
Syncope is a common problem which can be remarkably debilitating and associated with high health care costs; its true incidence is difficult to estimate due to variation in definition, differences in population prevalence and under reporting in the general population. The median peak of first syncope is around 15 years with a sharp increase after 70 years. Vasovagal syncope is the commonest cause of syncope for all age groups, but cardiac causes become more common with advancing age. The cumulative incidence of syncope ranges from $5 \%$ in females aged 20 to 29 , up to $50 \%$ in females aged 80 and above. Onethird of medical students report at least one syncopal episode in their life-time. The life-time cumulative incidence of syncope in women is almost twice that of men. Syncope accounts for up to $1-3 \%$ of hospital admissions and Emergency Room (ER) visits and in these settings is associated with cardiovascular co-morbidity and cardiovascular pharmacotherapy. In older adults syncope is a major cause of morbidity and mortality with enormous personal and wider health economic costs. Prevalence and incidence figures for syncope in older adults are confounded by an overlap with presentations classified as falls. In addition to injury and increasing dependency, quality-of-life studies consistently show that functional impairment in persons with recurrent syncope is similar to other chronic diseases.
\end{abstract}

\section{Keywords}

- Syncope;

- Prevalence;

- Incidence;

- Quality-of-life
Syncope has been defined by the European Society of Cardiology as a transient loss of consciousness (TLOC) due to transient global cerebral hypoperfusion characterised by rapid onset, short duration and spontaneous recovery. ${ }^{1}$ The annual healthcare cost of syncopal episodes in the United States was estimated in 2005 as $\$ 2.4$ billion per year for patients who were hospitalised, ${ }^{2}$ an amount that equated to $0.1 \%$ of the entire US Federal Government budget for that year. This compares with the treatment of asthma at $\$ 2.8$ billion, HIV at $\$ 2.1$ billion and chronic obstructive pulmonary disease at $\$ 1.9$ billion per year.
In non-economic terms syncope is a remarkably debilitating symptom. There are at present no financial estimates available, but Linzer et al. demonstrated that quality of life is seriously and adversely affected by syncope and, for those of working age, is frequently associated with loss of employment. ${ }^{3}$ Data from the Netherlands concur with this view. ${ }^{4}$

Syncope is a common problem in the population, but its true incidence is difficult to estimate due to variation of definition, differences in population prevalence and under reporting in the general population. For this review, we have focused on western populations and have chosen papers from 
Abbreviations and Acronyms

ER = Emergency Room

TILDA $=$ The Irish Longitudinal Study on Ageing

TLOC $=$ Transient loss of consciousness

times in the lifespan and in different settings.

\section{Syncope and the Framingham studies}

The Framingham series illustrates this difficulty of comparisons for the epidemiology of syncope vis-à-vis variations in definitions and methodologies. For example, in the first Framingham cohort of 1985 the authors reported a first syncope episode in $3 \%$ of men and $3.5 \%$ of women over a $26-$ year follow up period (mean age of cohort was 46 ranging from 30 to 62 years). Of these, the majority had experienced an isolated syncope. ${ }^{5}$

The cumulative incidence of syncope during a 4-year follow-up in the next Framingham Offspring study was $3 \%$ over a 4-year period (1991-1995), which was much higher than the first report. The age range in this instance was much broader -26 to 84 years. ${ }^{6}$

In the latest report of the Framingham Offspring study, syncope was defined differently from the previous studies and included subjects with seizures, strokes and transient ischaemic episodes evaluated over a 17 year follow up period. Ten percent of the 7814 participants (mean age 51 range 20-96 years) reported at least one episode of syncope. The median peak of first syncope was 15 years. The incidence rate of first syncope was 6.2 per 1000 person years. There was a sharp increase in incidence after 70 years from 5.7 events per
1000 person years in men aged 60 to 69 to 11.1 in men aged 70 to 79 - equivalent to an estimated 10 year cumulative incidence of $6 \%$ (Fig 1). Reflex syncope (labelled vasovagal) was the most common identifiable cause of syncope responsible for $21.2 \%$ of all episodes followed by cardiac syncope $(9.5 \%)$ and orthostatic hypotension (9.4\%). Overall, $44 \%$ of participants with a syncopal episode reported that they did not see a doctor or visit a hospital for evaluation. Syncope remained unexplained in $37 \%$ despite carrying out a detailed history, physical examination and electrocardiogram. ${ }^{7}$ Survival of patients with vasovagal syncope was equivalent to those who had not suffered syncope.

The cumulative incidence of syncope in the latter Framingham Study (all participants were older than 20 years and episodes of syncope were prospectively detailed) was $5 \%$ in females aged 20 to 29 and rose to $50 \%$ and $48 \%$ respectively in females and males aged 80 (Figs 1 and 2).

\section{Syncope in the young}

The results from the Framingham data are in sharp contrast with the Dutch senies of Ganzeboom et al. ${ }^{8}$ In 377 medical students the cumulative incidence of at least one syncopal episode rose from $8 \%$ before the age of 10 years to $47 \%$ in females and $24 \%$ in male students at the age of 24 years (Fig 2). ${ }^{8}$ At least one-third of medical students (mean age of 21 years) reported at least one syncopal episode in their lifetime. The majority of triggers involved stresses or conditions that affect orthostatic blood pressure regulation and therefore syncope was most likely reflex in the majority, if not all cases. The median age for the first episode of syncope was 15 years. The lifetime cumulative incidence of syncope in women was almost twice that of men. It is of interest that few females attributed reflex syncope to menstruation in the Dutch series. The authors attributed the gender difference to lower cardiac filling in women.

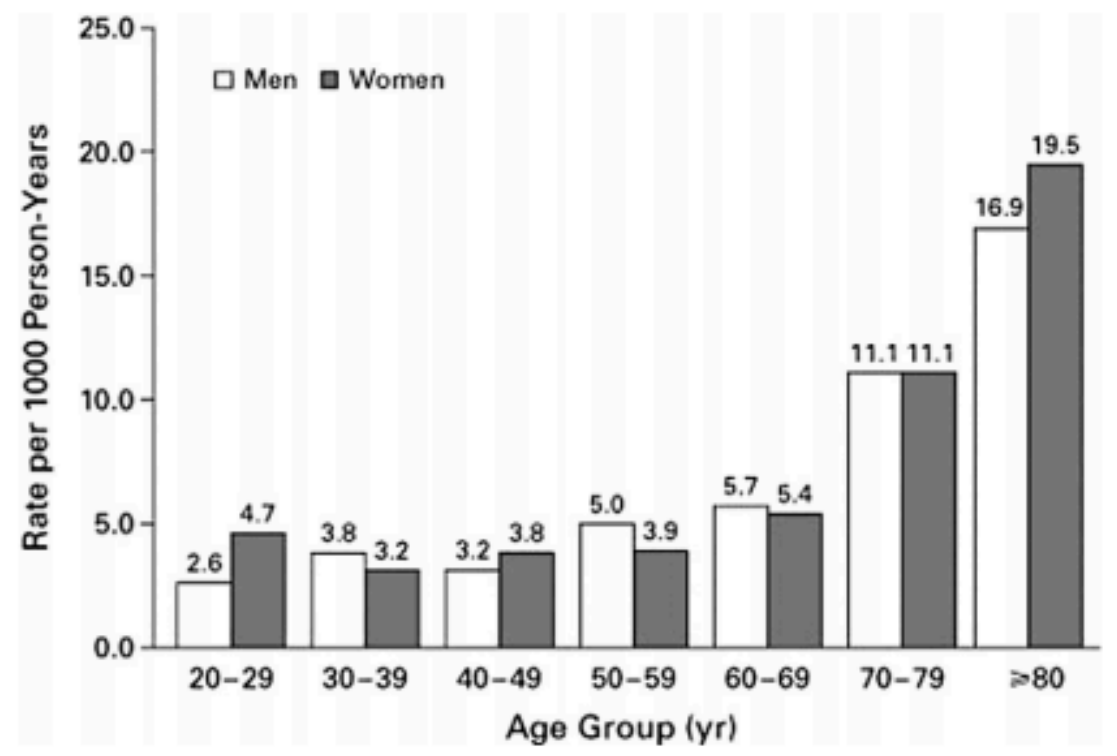

Fig 1 - Incidence rates of syncope according to age and sex. ${ }^{7}$ 




Fig 2 - Age-specific lifetime prevalence of syncope. ${ }^{8}$

Circumstances or triggers ranged from (i) warm environment $(31 \%)$, (ii) prolonged standing $27 \%$, (iii) pain $(25 \%)$, (iv) illness (18\%), (v) alcohol (13\%), (vi) emotion (11\%), (vii) venous puncture (10\%), (viii) standing ( $8 \%$ ), (ix) fasting (6\%), (x) fatigue (5\%), (xi) drugs (5\%), (xii) menstruation (6\%). Alcohol and drugs were significantly more common triggers in men, otherwise there was no gender difference (Table 1).

One Portuguese survey ${ }^{9}$ further characterised transient loss of consciousness emphasising gender differences, occupational factors and red flags for potentially dangerous cardiac causes using questions based on recent guidelines. ${ }^{10-12}$ Prevalence rates were similar to that reported in the Dutch series. The population was 2047 young working adults or students of whom 2011 completed a questionnaire. Twenty-nine percent reported previous transient loss of consciousness (TLOC), $21.9 \%$ had no episode in the past 5 years, $45.4 \%$ had only one episode, $30.8 \%$ had relapsing TLOC ( $2-5$ episodes in 5 years) and $1.9 \%$ very frequent TLOC (at least once monthly). Sixty-nine percent recorded falling, $33.1 \%$ had multiple triggers and $82.4 \%$ had premonitory symptoms. Independent predictors of TLOC were oral contraception, psychiatric drugs, epilepsy, a history of sudden death in a relative less than 50 years of age and a relative with a cardiac pacemaker. Seven percent and $8.9 \%$ of TLOC occurred during and after physical exercise respectively. In $13.4 \%$ of cases, episodes were associated with emotional stress: $11 \%$ with pain, $20 \%$ with fasting and $22 \%$ with a warm environment (Table 1).

Men were more likely to sustain an injury than women, had a higher prevalence of TLOC during physical exercise and TLOC without premonitory symptoms. A small subgroup (4\%) presented warning signs for a less benign prognosis i.e. TLOC and a history of sudden death in a relative under 50 , TLOC during physical exercise, TLOC due to fright or loud noise and sudden TLOC with no apparent reason.

The authors concluded that the clinical characteristics of the majority of young adults sustaining TLOC was suggestive of benign non-cardiac etiology, and the majority have

\begin{tabular}{|c|c|c|c|c|c|}
\hline & $\begin{array}{c}\text { Ganzeboom, et al. } \\
(2003)\end{array}$ & $\begin{array}{l}\text { Providencia, et al. } \\
\text { (2011) }\end{array}$ & $\begin{array}{l}\text { O'Dwyer, et al. } \\
\text { (2012) }\end{array}$ & $\begin{array}{c}\text { Graham, et al. } \\
\text { (2001) }\end{array}$ & $\begin{array}{l}\text { O'Dwyer, et al. } \\
\text { (2012) }\end{array}$ \\
\hline Number with syncope & $N=154 / 394$ & $N=598 / 2011$ & $\mathrm{~N}=219 / 219$ & $\mathrm{~N}=62 / 62$ & $\mathrm{~N}=92 / 92$ \\
\hline Mean age & $21 \mathrm{y}$ & $22 \mathrm{y}$ & $36 \mathrm{y}$ & $50 \mathrm{y}$ & $71 \mathrm{y}$ \\
\hline Warm environment & $31 \%$ & $22.3 \%$ & $23.6 \%$ & $37 \%$ & $23.9 \%$ \\
\hline Prolonged Stand & $27 \%$ & $11.9 \%$ & $54.9 \%$ & $27 \%$ & $51.1 \%$ \\
\hline Pain & $25 \%$ & $11.8 \%$ & $2.7 \%$ & & $1.1 \%$ \\
\hline Illness & $18 \%$ & $4.5 \%$ & $1.4 \%$ & & \\
\hline Alcohol & $13 \%$ & $7.9 \%$ & $10.1 \%$ & $10 \%$ & $2.2 \%$ \\
\hline Emotion & $11 \%$ & $13.4 \%$ & $21.7 \%$ & $21 \%$ & $7.6 \%$ \\
\hline Venipuncture & $10 \%$ & $13.2 \%$ & $15.1 \%$ & $11 \%$ & $3.3 \%$ \\
\hline Standing & $8 \%$ & & $79.8 \%$ & & $73.9 \%$ \\
\hline Fasting & $6 \%$ & $20.8 \%$ & & $23 \%$ & \\
\hline Fatigue & $5 \%$ & & & & \\
\hline Drugs & $5 \%$ & $1.5 \%$ & $5.9 \%$ & $10 \%$ & 38 \\
\hline Menstruation & $6 \%$ & & $0.9 \%$ & & \\
\hline Other & $10 \%$ & $3.9 \%$ & $3.7 \%$ & & \\
\hline Unknown & $3 \%$ & $2.5 \%$ & & & \\
\hline Epileptic features & & $1.5 \%$ & $5.5 \%$ & & $1.1 \%$ \\
\hline Accident & & $3.3 \%$ & & & \\
\hline Post prandial & & & $7.8 \%$ & & $14.1 \%$ \\
\hline Sitting & & & $36.7 \%$ & $19 \%$ & $43.5 \%$ \\
\hline During physical exercise & & $7.4 \%$ & $9.2 \%$ & & $3.3 \%$ \\
\hline After physical exercise & & $8.9 \%$ & $11 \%$ & & $1.1 \%$ \\
\hline Multiple triggers & $55 \%$ & $33 \%$ & $48 \%$ & & $37 \%$ \\
\hline
\end{tabular}

Note: Blank rows indicate trigger not reported. 
symptoms that were not investigated. In both of these series, the incidence of syncope is consistent with earlier studies in military personnel ${ }^{13-15}$ and much higher than reported in the Framingham Study. The most likely explanation for these differences is that in the Framingham study, only subjects who fainted during the study were asked if they had experienced syncope before entering the study. Other possible differences include the population (students versus working adults), age ranges, and case ascertainment influencing recall bias. Therefore, the Framingham data should probably not be used as an indicator for prevalence of syncope in younger populations. ${ }^{5-7}$

\section{Syncope in young athletes}

Because syncope may represent the initial presentation of several cardiac disorders in young athletes, concern usually exists over the evaluation of athletes who experience syncope. Possibly life threatening cardiac disorders include hypertrophic cardiomyopathy, left ventricular dysphasia, anomalous coronary artery origin, myocarditis and long QT syndrome. In one series of 33 athletes with recurrent unexplained syncope, all episodes were attributed to reflex syncope and the number of syncopal episodes during follow up was the only independent predictor of syncope recurrence. The authors concluded that recurrent exercise related syncope is not associated with adverse outcome in athletes who do not have cardiac disease. ${ }^{16}$

In a cohort of 7568 athletes undergoing pre-participation screening, $474(6.2 \%)$ experienced syncope in the previous 5 years. ${ }^{17}$ Most of the cases were unrelated to exercise, $12 \%$ were pre-exertion and $1.3 \%$ occurred during exercise. Of the latter 6 patients, one had hypertrophic obstructive cardiomyopathy, one had right ventricular outflow tachycardia and the remaining four athletes had reflex syncope confirmed by symptom reproduction during head up tilt testing.

All episodes of non-exertional or post-exertional syncope were attributed to neurally mediated (reflex) syncope. The recurrence rate was 20.3 per 1000 subject years. Exercise related syncope was infrequent and not associated with adverse outcome in subjects without cardiovascular abnormalities. The incidence of near syncope during competitive activity was particularly low.

\section{Syncope in older populations}

Syncope is a major cause of morbidity and mortality in older patients, with enormous personal and wider health economy costs. ${ }^{18}$ In addition to injury and increasing dependency, quality of life studies consistently show functional impairment similar to other chronic diseases including rheumatoid arthritis and epilepsy. 3,19,20

Increased susceptibility to syncope with advancing age is accounted for by age-related physiological impairments of heart rate and blood pressure regulation and alterations in cerebral blood flow combined with co-morbidities and polypharmacy. ${ }^{18,21}$ Data from a number of series ${ }^{5-8,22}$ document prevalence peaks at ages 15 and 70 years. Less recent studies indicate that the prevalence of syncope in an elderly institutionalised population is $23 \%$; with a 1 year incidence of $7 \%$ and a $30 \% 2$ year recurrence rate. ${ }^{23}$ The U.S. National Hospital Ambulatory Medical Centre Survey (1992-2000) reported 6.7 million attendances with syncope to the emergency department over this time period, which accounted for $0.77 \%$ of all attendances. There was a disproportionate burden on older patients in terms of hospitalisations, with $58 \%$ of sufferers over 80 years being admitted to hospital. ${ }^{24}$

Prevalence and incidence figures for syncope in older individuals may be significantly underestimated because of the overlap with presentations classified as falls. Patients with or without cognitive impairment will have difficulty remembering having fallen ${ }^{25,26}$ while the phenomenon of amnesia for loss of consciousness during syncope - vasovagal or carotid sinus syndrome - is well documented. ${ }^{27-29}$ The incidence of syncope in older patients is thus likely to be considerably higher than current estimates, with attendant cost implications. Because of the overlap with falls, the true incidence and therefore true costs of syncope to the health and social care systems and to labour market participation are unknown but likely to be considerably high. One recent population study, The Inish Longitudinal Study on Ageing (TILDA), ${ }^{30}$ has incorporated three syncope related questions.

TILDA is a population-based study of 8163 community dwelling adults over the age of 50, mean age 62 years-age range 50 to 105 years. Participants were asked if they had fainted in their youth, at anytime during their life and in the past 12 months. A percentage of 16.9 acknowledged fainting and $4.4 \%$ had fainted in the past 12 months. Recent fainters were more likely to be female, have cardiovascular or cerebrovascular disease (angina, heart attack, hypertension, stroke, TIA), and taking cardiovascular and/or psychotropic medications. Of fainters, $37.9 \%$ experienced one or more falls in past year compared with $18.3 \%$ of non-fainters. The prevalence of non-accidental falls (no trip or slip) was higher in fainters $42.2 \%$ compared with non-fainters $25.3 \%$. Therefore, combining a history of faints and a history of nonaccidental falls in the previous year the true prevalence ranged from 4.4 up to $8.8 \%{ }^{30}$

The causes of syncope are the same for all ages, although carotid sinus syndrome is almost exclusively diagnosed in adults over 50 years old. The relative frequency of different causes changes with age. ${ }^{21}$

\section{Syncope and hospital attendance}

A recent study from Denmark ${ }^{31}$ identified syncope and collapse from a large register of residents with a first time admission to hospital. Syncope was classified as a primary discharge diagnosis. The methodologies were well-validated in a sub-study and syncope patients were matched with five random controls from the Danish population. During the study period, between 1997 and 2009, a total of 127,508 patients were seen in the ER (45.3\%), in outpatient clinics $(11.7 \%)$ or in hospital (43\%). Of the syncope population, $52.6 \%$ were female. The age distribution of the sample showed 3 peaks, which is a new observation compared to previous studies that show only two peaks. The first peak was 
represented by females around 20 years of age, a second and quite smaller peak was seen in patients around 60 years of age and a third peak encompassed patients around 80 years of age. The largest proportion of syncope occurred in the age group 50 to 79 (35.7\%).

Syncope accounted for $0.9 \%$ of total admissions, and $0.6 \%$ of total ER visits. Of interest, during the study period there was an overall increase in the incident rates of syncope of 13.8 to 19.4 per 1000 person years. This observation has been previously reported from US and UK national databases. ${ }^{32}$

Similar to the TILDA study, ${ }^{30}$ syncope in the Danish study $^{31}$ was associated with marked cardiovascular comorbidity and use of cardiovascular pharmacotherapy across all age groups when compared with the control population. Twenty-eight percent of the overall population had cardiovascular disease compared with $14 \%$ of the control population. Nearly half $(48 \%)$ of the syncope population were medicated with one or more types of cardiovascular specific medication as compared to $38 \%$ of the control population. The association with cardiovascular medication was even more pronounced in the 50-79 year old age group (66\% versus $51 \%$ ) and reinforces the importance of cardiovascular co-morbidity and pharmacotherapy when evaluating a patient with syncope. ${ }^{33}$

\section{Syncope in general practice}

Data from a large general practitioner database in the Netherlands revealed that 2-9 per thousand encounters were due to blackouts or fainting. Reflex syncope was the most likely underlying condition. The age distribution of these patients showed a peak in females around 15 years and a second peak in older patients over the age of 65 .

General practitioners in the Netherlands refer only $10 \%$ of patients with reflex syncope to specialists for further evaluation. In most cases, referrals are made to a neurologist or to a cardiologist. ${ }^{22}$ The reasons for referral are atypical fainting. Only a very small fraction of patients with syncope in the general population present in any clinical setting. If we take syncopal - per 1000 patient years - the prevalence is anywhere from 18.1 to 39.7 in the general population of whom 9.3 attend their general practice because of the event and 0.7 present to the $\mathrm{ER}^{8}$ (Fig 3).

\section{Syncope in the Emergency Room (ER)}

The prevalence of syncope referrals to emergency departments range from $0.9 \%$ to $3.4 \% .{ }^{34,35}$ Reflex syncope is the most common cause (up to $40 \%$ ), orthostatic hypotension occurs in 6-24\%, cardiac syncope $10-20 \%$, psychogenic syncope $1-5 \%$ (Fig 4). ${ }^{22}$ Cardiac causes and orthostatic hypotension are more common in the older patient. Although cardiac syncope and orthostatic hypotension are more common causes of syncope in older persons, reflex syncope is also common and is being diagnosed with increasing frequency in this age group. ${ }^{22}$ Vasovagal syncope in older adults may not necessarily follow the benign course ${ }^{36}$ commonly observed in young patients. ${ }^{37}$ Older patients are more likely to have concurrent comorbidity and be taking concurrent medications. ${ }^{31}$
Syncope events/visits per 1000 patient-years
General population

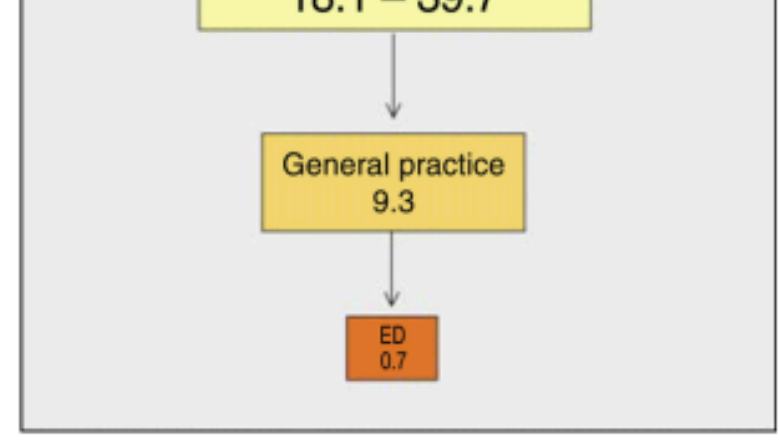

Fig 3 - Frequency of the causes of syncope in general population, emergency department and specialized clinical settings from some recent studies adapted from the Guidelines for the diagnosis and management of syncope Moya et al. 2009. ${ }^{1}$
$18.1-39.7$

\section{Prevalence and causes of syncope}

The prevalence and causes of syncope are different depending on the clinical setting in which the patient is evaluated and the age of patients (Table 2). Furthermore, there are differences in diagnostic definitions, geographical factors, and local care pathways, making a comparison between different studies very difficult. The European Society of Cardiology ${ }^{1}$ has in this context provided a number of

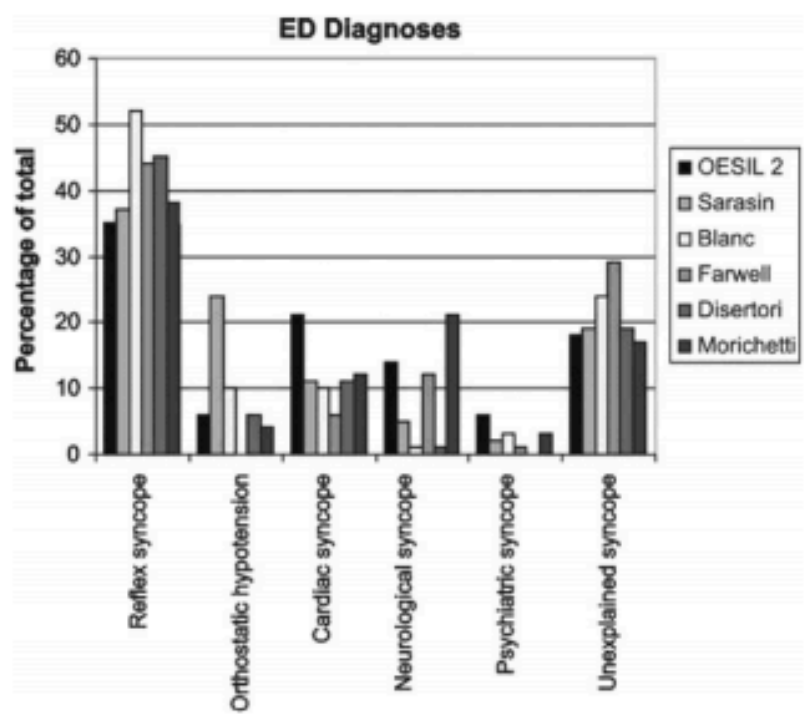

Fig 4 - Frequency of causes of syncope in European emergency departments. ${ }^{22}$ 
Table 2-Syncope frequency depends on the setting in which the measurement is made. ${ }^{32}$

\begin{tabular}{lll} 
& \multicolumn{1}{c}{$\begin{array}{c}\text { Incident (Per 1000 } \\
\text { Patient-Years) }\end{array}$} & \multicolumn{1}{c}{ Ratio } \\
\hline General population & $18-40$ & 1 \\
Seeking medical evaluation & $9.3-9.5$ & $1: 2-1: 4$ \\
Referred for specialty evaluation & 3.6 & $1: 5-1: 10$ \\
$\begin{array}{l}\text { Referred to emergency } \\
\text { department }\end{array}$ & $0.7-1.8$ & $1: 10-1: 50$ \\
\hline Adapted from Olde Nordkamp et al. & \\
\hline
\end{tabular}

general comments with respect to prevalence of causes of syncope.

1. Reflex syncope is the most frequent cause in any age group.

2. Syncope secondary to cardiovascular disease is the second most common cause. The number of the patients with cardiovascular causes varies widely between studies with higher frequencies in the emergency setting, in older subjects and in settings orientated towards cardiology.

3. In patients under 40 , orthostatic hypotension is a rare cause of syncope, whereas it is frequent in very old patients.

4. Non-syncopal conditions are more frequent in emergency referrals and reflect multifactorial complexity of these patients.

5. High unexplained syncope rate in all settings justifies new strategies for evaluation and diagnosis.

Whilst in the young reflex syncope is by far the most frequent cause of TLOC, in older patients multiple causes are often present and the medical history may be less reliable. ${ }^{21,38-44}$ The causes of syncope will be covered in detail elsewhere in this issue.

\section{Conclusion}

In conclusion, syncope is a common problem in the general population. Its age distribution is bi-modal or tri-modal according to recent studies, peaking in teenagers and the elderly. Although several studies have been performed with young subjects, the incidence of syncope in the elderly in the general population is less well studied, with the exception of the recent TILDA dataset.

The lifetime cumulative incidence of syncope is much higher in women than in men. Reflex syncope remains more frequent than any other cause of syncope, although cardiac syncope, orthostatic and post-prandial hypotension and the effects of medications are more common causes of syncope in the elderly. Carotid sinus syndrome is also uniquely a cause of syncope in older subjects.

Reflex syncope is in general benign, although again, this has been poorly studied in elderly populations. A recent Danish study ${ }^{31}$ has emphasised a significant association between cardiovascular co-morbidity, pharmacotherapy and syncope in patients who present to hospital emphasising the importance of detailed evaluation of the patient for more serious underlying co-morbidity.

\section{Statement of Conflict of Interest}

The authors of this article have no pertinent conflicts of interest to report.

\section{REFERENCES}

1. Moya A, Brignole $\mathrm{M}$, et al. Guidelines for the diagnosis and management of syncope (version 2009): The Task Force for the Diagnosis and Management of Syncope of the European Society of Cardiology (ESC). Eur Heart J. 2009;30(21):2631-2671.

2. Sun BC, Emond JA, Camargo CA. Direct medical costs of syncope-related hospitalizations in the United States. Am J Cardiol. 2005;95(5):668-671.

3. Linzer M, Pontinen M, Gold DT, Divine GW, Felder A, Brooks WB. Impairment of physical and psychosocial function in recurrent syncope. J Clin Epidemiol. 1991;44(10):1037-1043.

4. van Dijk N, Sprangers MA, Boer KR, Colman N, Wieling W, Linzer M. Quality of life within one year following presentation after transient loss of consciousness. Am J Cardiol. 2007;100(4):672-676.

5. Savage DD, Corwin L, McGee DL, Kannel WB, Wolf PA. Epidemiologic features of isolated syncope: the Framingham Study. Stroke. 1985;16(4):626-629.

6. Freed LA, Levy D, Levine RA, et al. Prevalence and clinical outcome of mitral-valve prolapse. N Engl J Med. 1999;341(1):1-7.

7. Soteriades ES, Evans JC, Larson MG, et al. Incidence and Prognosis of Syncope. N Engl J Med. 2002;347(12):878-885.

8. Ganzeboom KS, Colman N, Reitsma JB, Shen WK, Wieling W. Prevalence and triggers of syncope in medical students. Am J Cardiol 2003; 91(8): 1006-1008, A8.

9. Providencia R, Silva J, Mota P, Nascimento J, Leitao-Marques A. Transient loss of consciousness in young adults. Int J Cardiol. 2011;152(1):139-143.

10. Corrado D, Pelliccia A, Bjornstad HH, et al. Cardiovascular preparticipation screening of young competitive athletes for prevention of sudden death: proposal for a common European protocol: Consensus Statement of the Study Group of Sport Cardiology of the Working Group of Cardiac Rehabilitation and Exercise Physiology and the Working Group of Myocardial and Pericardial Diseases of the European Society of Cardiology. Eur Heart J. 2005;26(5):516-524.

11. IOC: International Olympic Committee (IOC) Medical Commission. IOC preparticipation cardiovascular screening. Available at: $\mathrm{http}: / /$ multimedial.olympic.org/pdf/ en_report_886.pdf. December 10 2004. (11 November 2010 date last accessed).

12. Maron BJ, Thompson PD, Ackerman M), et al. Recommendations and Considerations Related to Preparticipation Screening for Cardiovascular Abnormalities in Competitive Athletes: 2007 Update: A Scientific Statement From the American Heart Association Council on Nutrition, Physical Activity, and Metabolism: Endorsed by the American College of Cardiology Foundation. Circulation. 2007;115(12):1643-1655.

13. Dermksian G, Lamb LE. Syncope in a population of healthy young adults; incidence, mechanisms, and significance. J Am Med Assoc. 1958;168(9):1200-1207. 
14. Lamb LE, Green HC, Combs JJ, Cheeseman SA, Hammond J. Incidence of loss of consciousness in 1,980 Air Force personnel. Aerosp Med. 1960;31-973-988.

15. Murdoch BD. Loss of consciousness in healthy South African men: Incidence, causes and relationship to EEG abnormality. $S$ Afr Med J. 1980;57(19):771-774.

16. Colivicchi F, Ammirati F, Biffi A, Verdile L, Pelliccia A, Santini M. Exercise-related syncope in young competitive athletes without evidence of structural heart disease. Clinical presentation and long-term outcome. Eur Heart J. 2002;23(14): $1125-1130$

17. Colivicchi F, Ammirati F, Santini M. Epidemiology and prognostic implications of syncope in young competing athletes. Eur Heart J. 2004;25(19):1749-1753.

18. Marrison VK, Fletcher A, Parry SW. The older patient with syncope: practicalities and controversies. Int J Cardiol. 2012;155(1):9-13.

19. Santhouse J, Carrier C, Arya S, Fowler H, Duncan S. A comparison of self-reported quality of life between patients with epilepsy and neurocardiogenic syncope. Epilepsia. 2007;48(5):1019-1022.

20. van Dijk N, Sprangers MA, Colman N, Boer KR, Wieling W, Linzer M. Clinical factors associated with quality of life in patients with transient loss of consciousness. J Cardiovasc Electrophysiol. 2006;17(9):998-1003.

21. Kenny RA. Syncope in the elderly: diagnosis, evaluation, and treatment. J Cardiovase Electrophysiol. 2003;14(9 Suppl):S74-S77.

22. Colman N, Nahm K, Ganzeboom KS, et al. Epidemiology of reflex syncope. Clin Auton Res. 2004;14(Suppl 1):9-17.

23. Lipsitz LA, Wei JY, Rowe JW. Syncope in an elderly, institutionalised population: prevalence, incidence, and as sociated risk. QJ Med. 1985;55(216):45-54.

24. Sun BC, Emond JA, Camargo CA. Characteristics and admission patterns of patients presenting with syncope to U.S. emergency departments, 1992-2000. Acad Emerg Med. 2004;11(10):1029-1034.

25. Shaw FE, Kenny RA. The overlap between syncope and falls in the elderly. Postgrad Med J. 1997;73(864):635-639.

26. Cummings SR, Nevitt MC, Kidd S. Forgetting falls. The limited accuracy of recall of falls in the elderly. J Am Geriatr Soc. 1988;36(7):613-616.

27. Mcintosh S, Costa DD, Kenny RA. Outcome of an integrated approach to the investigation of dizziness, falls and syncope, in elderly patients referred to a 'syncope' clinic. Age Ageing. 1993;22(1):53-58.

28. Parry SW, Steen IN, Baptist M, Kenny RA. Amnesia for loss of consciousness in carotid sinus syndrome: implications for presentation with falls. J Am Coll Cardiol. 2005;45(11):1840-1843.

29. O'Dwyer C, Bennett K, Langan Y, Fan CW, Kenny RA. Amnesia for loss of consciousness is common in vasovagal syncope. Europace. 2011;13(7):1040-1045.
30. Kenny R, King-Kallimanis B: Epidemiology of Syncope/Collapse in adults 50 years and older-The Irish Longitudinal study on Ageing. In Preparation.

31. Ruwald MH, Hansen ML, Lamberts M, et al. The relation between age, sex, comorbidity, and pharmacotherapy and the risk of syncope: a Danish nationwide study. Europace. 2012;14(10):1506-1514.

32. Brignole M, Hamdan MH. New concepts in the assessment of syncope. J Am Coll Cardiol. 2012;59(18):1583-1591.

33. Kapoor WN, Hanusa BH. Is syncope a risk factor for poor outcomes? Comparison of patients with and without syncope. Am J Med. 1996;100(6):646-655.

34. Casini-Raggi V, Bandinelli G, Lagi A. Vasovagal syncope in emergency room patients: analysis of a metropolitan area registry. Neuroepidemiology. 2002;21(6):287-291.

35. McCarthy F, McMahon CG, Geary U, Plunkett PK, Kenny RA, Cunningham CJ. Management of syncope in the Emergency Department: a single hospital observational case series based on the application of European Society of Cardiology Guidelines. Europace. 2009;11(2): 216-224.

36. Duncan GW, Tan MP, Newton JL, Reeve P, Parry SW. Vasovagal syncope in the older person: differences in presentation between older and younger patients. Age Ageing. 2010;39(4): 465-470.

37. Alboni $\mathrm{P}$, Brignole $\mathrm{M}$, degli Uberti EC. Is vasovagal syncope a disease? Europace. 2007;9(2):83-87.

38. Chen LY, Gersh BJ, Hodge DO, Wieling W, Hammill SC, Shen WK. Prevalence and clinical outcomes of patients with multiple potential causes of syncope. Mayo Clin Proc. 2003;78(4):414-420.

39. Romme J, van Dijk N, Boer KR, et al. Influence of age and gender on the occurrence and presentation of reflex syncope. Clin Auton Res. 2008;18(3):127-133.

40. Del Rosso A, Alboni P, Brignole M, Menozzi C, Raviele A. Relation of clinical presentation of syncope to the age of patients. Am J Cardiol. 2005;96(10):1431-1435.

41. Graham LA, Kenny RA. Clinical characteristics of unexplained syncope and their relationship to tilt table test outcomes. Clin Auton Res. 2002;12(2):88-93.

42. Olde Nordkamp LR, van Dijk N, Ganzeboom KS, et al. Syncope prevalence in the ED compared to general practice and population: a strong selection process. Am J Emerg Med. 2009;27(3):271-279.

43. Malasana G, Brignole M, Daccarett M, Sherwood R, Hamdan MH. The prevalence and cost of the faint and fall problem in the state of Utah. Pacing Clin Electrophysiol. 2011; 34(3):278-283.

44. O'Dwyer C, Kenny RA. Prodome and characteristics of young and old patients presenting with vasovagal syncope to a teaching hospital. Age Ageing. 2010;39(Suppl 1):20. 